\title{
Growth of MWCNTs on Flexible Stainless Steels without Additional Catalysts
}

\author{
Udomdej Pakdee, ${ }^{1}$ Surasak Chiangga, ${ }^{1}$ Suchat Suwannatus, ${ }^{1}$ and Pichet Limsuwan ${ }^{2,3}$ \\ ${ }^{1}$ Department of Physics, Faculty of Science, Kasetsart University, Bangkok 10900, Thailand \\ ${ }^{2}$ Department of Physics, Faculty of Science, King Mongkut's University of Technology Thonburi, Bangkok 10140, Thailand \\ ${ }^{3}$ Thailand Center of Excellence in Physics, CHE, Ministry of Education, Bangkok 10400, Thailand
}

Correspondence should be addressed to Udomdej Pakdee; g5717400136@ku.ac.th and Surasak Chiangga; fscissc@ku.ac.th

Received 12 February 2017; Accepted 1 March 2017; Published 28 March 2017

Academic Editor: Andrew R. Barron

Copyright (C) 2017 Udomdej Pakdee et al. This is an open access article distributed under the Creative Commons Attribution License, which permits unrestricted use, distribution, and reproduction in any medium, provided the original work is properly cited.

\begin{abstract}
Multiwalled carbon nanotubes (MWCNTs) were synthesized on austenitic stainless steel foils (Type 304) using a home-built thermal chemical vapor deposition (CVD) under atmospheric pressure of hydrogen $\left(\mathrm{H}_{2}\right)$ and acetylene $\left(\mathrm{C}_{2} \mathrm{H}_{2}\right)$. During the growth, the stainless steel substrates were heated at different temperatures of $600,700,800$, and $900^{\circ} \mathrm{C}$. It was found that MWCNTs were grown on the stainless steel substrates heated at 600,700 , and $800^{\circ} \mathrm{C}$ while amorphous carbon film was grown at $900^{\circ} \mathrm{C}$. The diameters of MWCNTs, as identified by scanning electron microscope (SEM) images together with ImageJ software program, were found to be $67.7,43.0$, and $33.1 \mathrm{~nm}$, respectively. The crystallinity of MWCNTs was investigated by an X-ray diffractometer. The number of graphitic walled layers and the inner diameter of MWCNTs were investigated using a transmission electron microscope (TEM). The occurrence of $\mathrm{Fe}_{3} \mathrm{O}_{4}$ nanoparticles associated with carbon element can be used to reveal the behavior of $\mathrm{Fe}$ in stainless steel as catalyst. Raman spectroscopy was used to confirm the growth and quality of MWCNTs. The results obtained in this work showed that the optimum heated stainless steel substrate temperature for the growth of effective MWCNTs is $700^{\circ} \mathrm{C}$. Chemical states of MWCNTs were investigated by X-ray photoelectron spectroscopy (XPS) using synchrotron light.
\end{abstract}

\section{Introduction}

Multiwalled carbon nanotubes (MWCNTs) have been widely studied by many researchers. MWCNTs can be synthesized by different methods such as arc discharge [1-5], laser ablation $[6,7]$, chemical vapor deposition (CVD) [8-15], and flame method [16-19]. Most of these processes have been generally prepared in vacuum or with process gases. Among these processes, the CVD is one of the most popular processes used for the growth of MWCNTs. The advantages of CVD are being a simple method, having low cost, and being suitable for large scale fabrication. In the CVD process, the catalyst is one of the key factors for MWCNTs growth. Nickel [20, 21], cobalt [22, 23], iron [24, 25], stainless steel [26-34], gold [35], platinum [36], and their alloys have been effectively used as catalysts. One of these metals is generally deposited on the substrate in the form of thin film as a catalyst before the growth of MWCNTs. For stainless steel, the main compositions are $\mathrm{Fe}, \mathrm{Ni}, \mathrm{Mn}$, and $\mathrm{Cr}$. Therefore, the large scale MWCNTs can be fabricated directly on stainless steel surface without an addition of extra catalysts [28]. However, only Fe and Ni play the role as catalysts for stainless steel [29]. In some applications such as a small area of electronic devices, the flexibility of substrate is necessary to be considered. Recently, MWCNTs have been synthesized on flexible substrates such as graphite foil [37], aluminum foil [38], and copper foil [3942]. Significantly, these substrates are considered as a poor catalyst in general for the growth of MWCNTs. Consequently, an additional extra catalyst is necessary. However, the addition of catalytic layers may increase the electrical resistance between MWCNTs and substrates. This disadvantage may be solved by using the direct growth of MWCNTs on conductive substrates without additional catalysts. More importantly, there are not many reports on the growth of MWCNTs on stainless steel foil although a lot of works on the growth of MWCNTs on the inflexible heavy stainless steel have been 


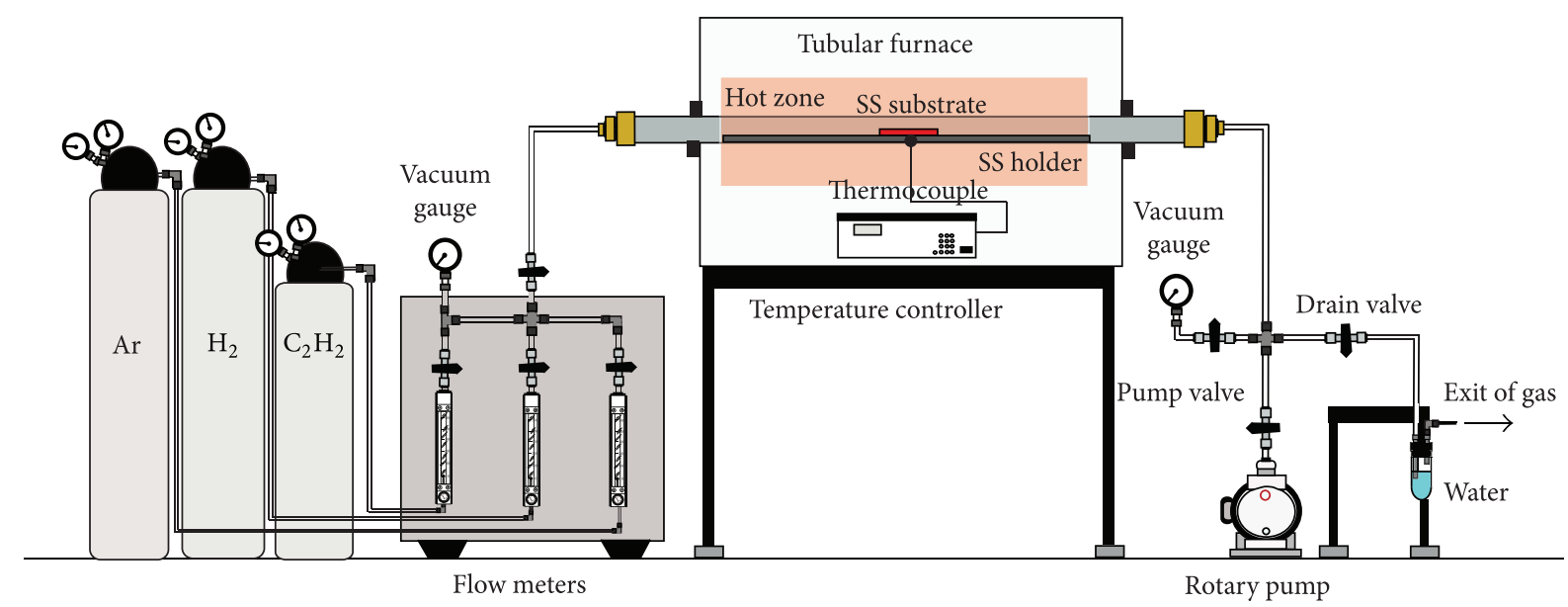

FIgURE 1: Schematic illustration of thermal CVD system.

reported. The MWCNTs grown on the flexible substrate are suitable for flexible battery device development [43] while amorphous carbon films are effectively used for flexible absorbers [44].

In this work, a home-built thermal CVD system was designed and constructed for growing MWCNTs. The austenitic stainless steel foil (Type 304) was used as flexible substrate. It also behaves as catalyst and, hence, no need for an addition of extra catalyst for synthesizing MWCNTs. Furthermore, during the growth of MWCNTs, the stainless steel substrates were heated at different temperatures of 600 , 700,800 , and $900^{\circ} \mathrm{C}$ under atmospheric pressure of hydrogen $\left(\mathrm{H}_{2}\right)$ and acetylene $\left(\mathrm{C}_{2} \mathrm{H}_{2}\right)$. The effects of heated stainless steel substrate temperatures on the growth of MWCNTs were also reported.

\section{Materials and Methods}

2.1. Chemical Vapor Deposition System. Figure 1 shows the schematic illustration of thermal CVD system. It consists of tubular furnace (Nabertherm, R 60/750/12-B 170), gas system, rotary pump (Alcatel, 2012), and water system.

The tubular furnace was used as a heating source in CVD system. It consists of an alumina tube with an inner diameter of $6 \mathrm{~cm}$ and a length of $150 \mathrm{~cm}$. The dimension of the furnace is $35 \mathrm{~cm} \times 100 \mathrm{~cm} \times 60 \mathrm{~cm}$. The heating source is electrical wire winding around the alumina tube with a power of $3.6 \mathrm{~kW}$. The furnace can be heated up to a maximum temperature of $1200^{\circ} \mathrm{C}$ using a programmable temperature controller.

Argon (Ar), hydrogen $\left(\mathrm{H}_{2}\right)$, and acetylene $\left(\mathrm{C}_{2} \mathrm{H}_{2}\right)$ gases were used as raw materials for the gas system. Three flow meters (Cole-Parmer, TW03227-12) were used to control the flow rate of gases from 0 to $200 \mathrm{sccm}$. The pressure inside the tube was measured by vacuum gauges (ENFM, 7011). The ball valves (Swagelok, B-42S4) were used to open/close all three gases. A rotary pump was used to evacuate and remove the oxygen out of the tube before supplying argon, hydrogen, and acetylene gases into the alumina tube.
The water system consists of a glass tube with an inner diameter of $3.5 \mathrm{~cm}$ and a length of $10 \mathrm{~cm}$. The glass tube was filled with water of about $100 \mathrm{~cm}^{3}$. The drain valve (Swagelok, B-42S4) was connected between the high temperature gases and glass tube. The drain valve was managed to open when the pressure within the alumina tube was higher than the atmospheric pressure to protect the water feed back into the alumina tube. The exhausted gas was cooled down by water before it was drained out.

2.2. Preparation of Stainless Steel Foils as Substrates. In this study, to protect the contamination of alumina tube inner surface, a stainless steel tube with an inner diameter of $4.9 \mathrm{~cm}$, $1 \mathrm{~mm}$ thick and $150 \mathrm{~cm}$ long, was fabricated and placed in the alumina tube of tubular furnace. Figure 2 shows the schematic illustration of the stainless steel tube with the brass coupling holder. It was inserted along the alumina tube inner surface of the furnace. Each end of the stainless steel tube was inserted through a brass holder and tightening with an O-ring. The other side of the brass holder was inserted with a copper tube also tightening with an O-ring. The tip of the copper tube was slightly inserted in the stainless tube. The gas was allowed to pass through the copper tube from the left end of the brass holder into the stainless steel tube.

The austenitic stainless steel foils (Type 304) with a thickness of approximately $50 \mu \mathrm{m}$ and RMS roughness of $9.93 \mathrm{~nm}$, purchased from Nippon Kinzoku, were used as substrates. They were cut into a size of $1.6 \mathrm{~cm} \times 3 \mathrm{~cm}$, cleaned, and rinsed using hydrochloric acid 35\% and methanol 99.99\%, respectively. A stainless steel plate with a size of $3 \mathrm{~cm} \times 100 \mathrm{~cm} \times$ $0.1 \mathrm{~cm}$ was used as the substrate holder.

2.3. Synthesis of Carbon Nanotubes. The substrates were placed in the stainless steel tube and evacuated with a rotary pump until the pressure inside the stainless steel tube was less than $10^{-2}$ mbar. To prevent the oxidation of surface stainless steel substrate surface, Ar was fed into the stainless steel tube with a flow rate of 50 standard cubic centimeters per minute $(\mathrm{sccm})$. At the same time, the stainless steel tube was heated 


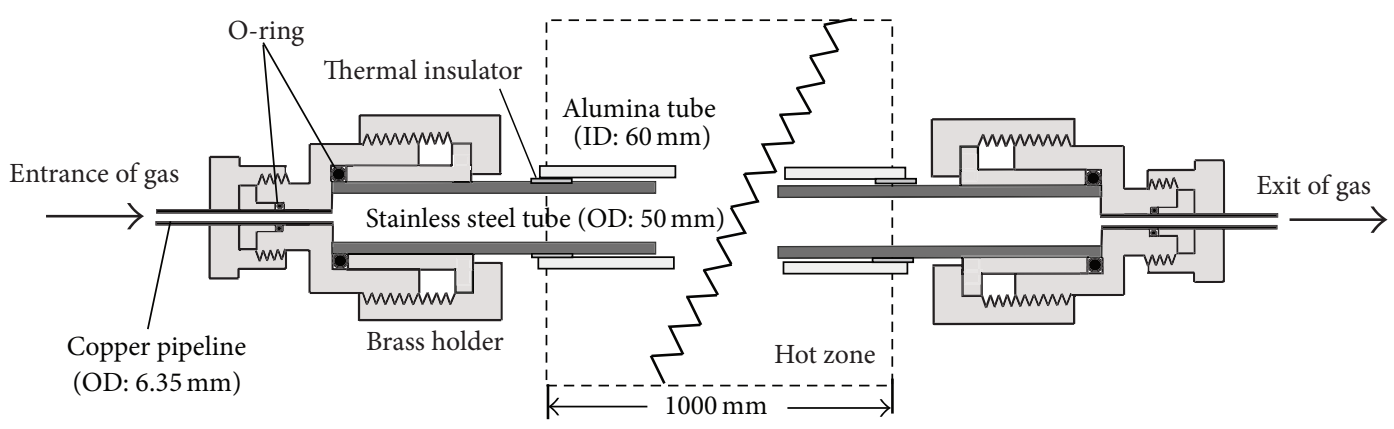

FIGURE 2: Schematic illustration of stainless steel tube with the brass coupling holder inserted in the alumina tube of the tubular furnace.

up to $600^{\circ} \mathrm{C}$. Then, the valve of a rotary pump was closed until the pressure in the stainless steel tube was higher than atmospheric pressure and the drain valve was opened for gas exit. The exhausted gas was cooled down by the water and drained afterwards. $\mathrm{H}_{2}$ used as reductive gas was injected into the stainless steel tube with a flow rate of $200 \mathrm{sccm}$ for $30 \mathrm{~min}$ to etch the oxide on the substrate surface. After that, $\mathrm{C}_{2} \mathrm{H}_{2}$ was fed into the stainless steel tube with a flow rate of $160 \mathrm{sccm}$ for $30 \mathrm{~min}$. Finally, the MWCNTs were formed at $600^{\circ} \mathrm{C}$ and they were cooled down using Ar with a flow rate of $50 \mathrm{sccm}$ until it reached the room temperature. The above process was repeated for the heating temperatures of 700,800 , and $900^{\circ} \mathrm{C}$, respectively.

\subsection{Characterization}

2.4.1. Sample Preparation. The black carbon films grown on a stainless steel foil substrate were scraped off by a plastic sheet and divided into two equal parts. The first part was used to determine the crystallinity, chemical bonding and morphology by X-ray diffractometer (XRD), Fourier transform Raman (FT-Raman) spectrometer, and scanning electron microscope (SEM), respectively. The second part was used to verify the hollow tube using a transmission electron microscope (TEM).

2.4.2. Scanning Electron Microscopy. Scanning electron microscopy (SEM, Quanta $450 \mathrm{FEI}$ ) was used to investigate the morphology of the MWCNTs. The operating voltage and current were $30 \mathrm{kV}$ and $10 \mu \mathrm{A}$, respectively. The working distance of $6.7 \mathrm{~mm}$ was used for SEM imaging analysis. The diameter of MWCNTs was identified by analyzing SEM images with the ImageJ public software program supplied by the National Institutes of Health (NIH).

2.4.3. X-Ray Diffraction. X-ray diffraction (XRD, Bruker D8 Advance) was used to determine the crystallinity of MWCNTs. The MWCNTs were scanned over the diffraction angle $2 \theta$ of 10 to 75 degrees. The scanning speed was set at 3 degrees/min with a step of $0.02^{\circ}$. The incident $\mathrm{X}$-ray wavelength was 1.54 angstrom ( $\mathrm{Cu}$ anode) with the voltage and current of $40 \mathrm{kV}$ and $40 \mathrm{~mA}$, respectively.
2.4.4. Transmission Electron Microscopy. The MWCNTs were sonicated with ethanol for $15 \mathrm{~min}$ and dropped on a copper grid. Then, they were taken into the holder of electron microscope. Transmission electron microscopy (TEM, Hitachi HT 7700 ) was conducted using an accelerating voltage of $120 \mathrm{kV}$ for low resolution and $200 \mathrm{kV}$ for high resolution with a current of $60 \mu \mathrm{A}$ to investigate the structure of MWCNTs.

2.4.5. X-Ray Photoelectron Spectroscopy. X-ray photoelectron spectroscopy (XPS, ULVAC-PHI) with $\mathrm{Al} \mathrm{K}$ radiation as the excitation source at the Synchrotron Light Research Institute (SLRI), Thailand, was used for the characterization of chemical composition and chemical states of MWCNTs. The binding energy was calibrated using the Cls peak $(284.6 \mathrm{eV})$ as a reference. Gaussian-Lorentzian function, after performing Shirley background subtraction, was used for XPS peak deconvolution.

2.4.6. Fourier Transform Raman Spectroscopy. Fourier transform Raman spectroscopy (Perkin Elmer Spectrum GX) was also used to confirm the growth of MWCNTs and identify the crystallinity. The laser with a power of $80 \mathrm{~mW}$ and a working wavelength of $1024 \mathrm{~nm}$ was used as a light source. The laser beam was focused onto the sample surface with a spot area of $1 \mathrm{~mm}^{2}$.

\section{Results and Discussion}

Figure 3 shows the SEM images of carbon films grown on the stainless steel substrates heated at different temperatures of $600,700,800$, and $900^{\circ} \mathrm{C}$. It is clearly observed that the MWCNTs were grown on the substrates with random orientation in the temperature range of $600-800^{\circ} \mathrm{C}$ (Figures $3(\mathrm{a})-3(\mathrm{c}))$. However, the better uniformity of MWCNTs was observed on the substrate heated at $700^{\circ} \mathrm{C}$ (Figure 3(b)). Furthermore, the amorphous carbon was observed on the substrate heated at $900^{\circ} \mathrm{C}$ as shown in Figure 3(d).

Figures 4(a)-4(c) show the size distribution of MWCNTs and Figure 4(d) shows the size distribution of amorphous carbon. As can be seen in Figures 4(a)-4(c), the diameter of MWCNTs decreased with increasing heated substrate temperature. The average diameters of MWCNTs grown on heated substrates temperature of 600,700 , and $800^{\circ} \mathrm{C}$ are 67.7 


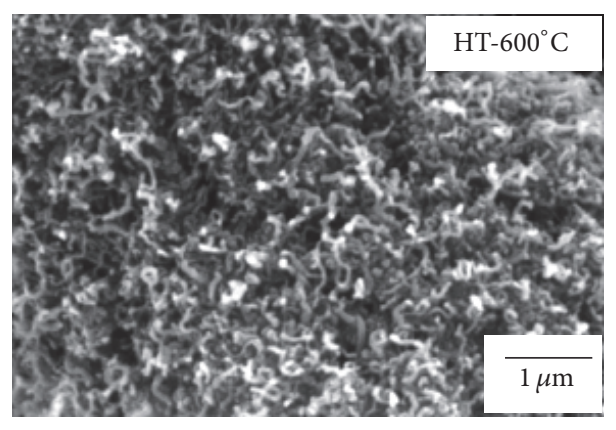

(a)

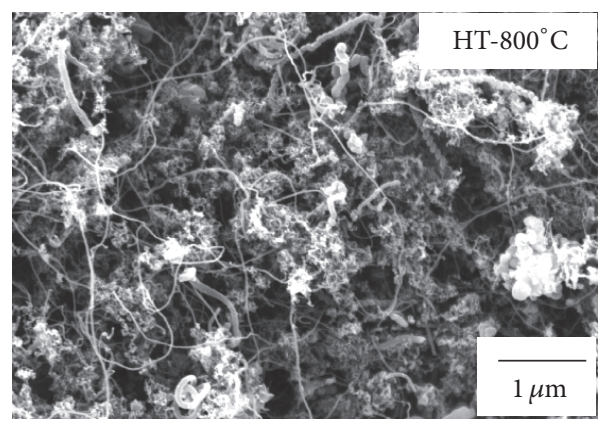

(c)

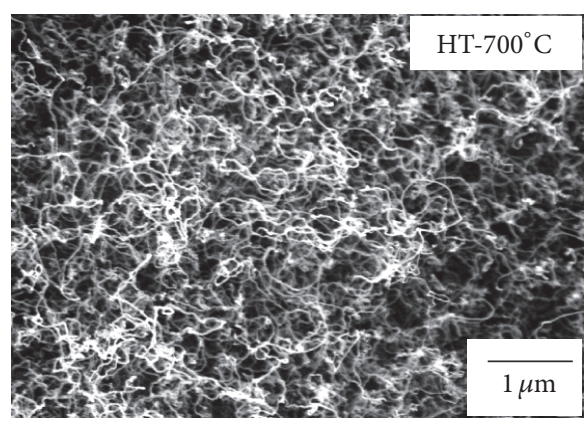

(b)

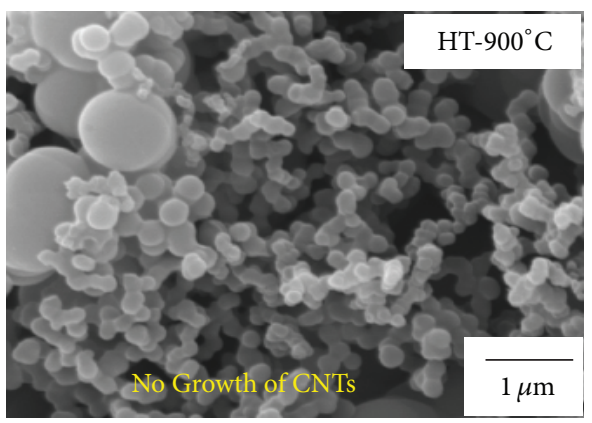

(d)

FIGURE 3: SEM images of carbon films grown on heated substrates at different temperatures of $600-900^{\circ} \mathrm{C}$.

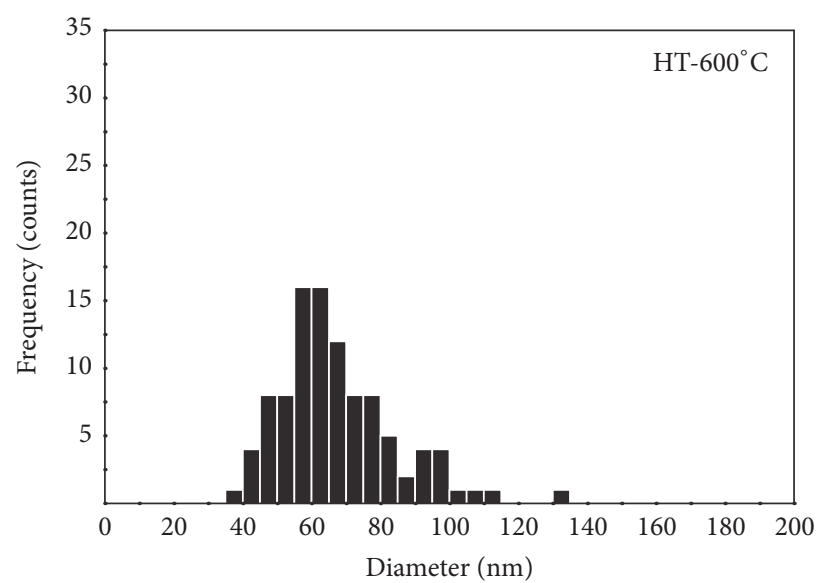

(a)

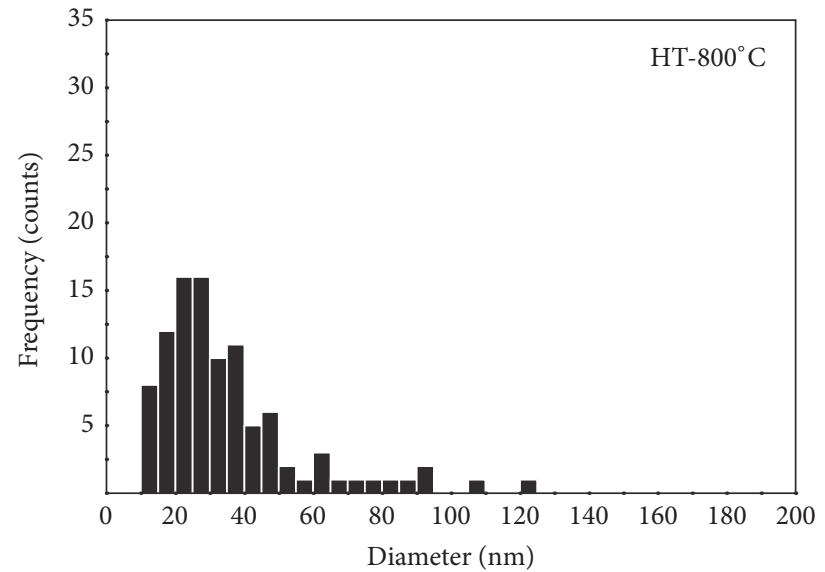

(c)

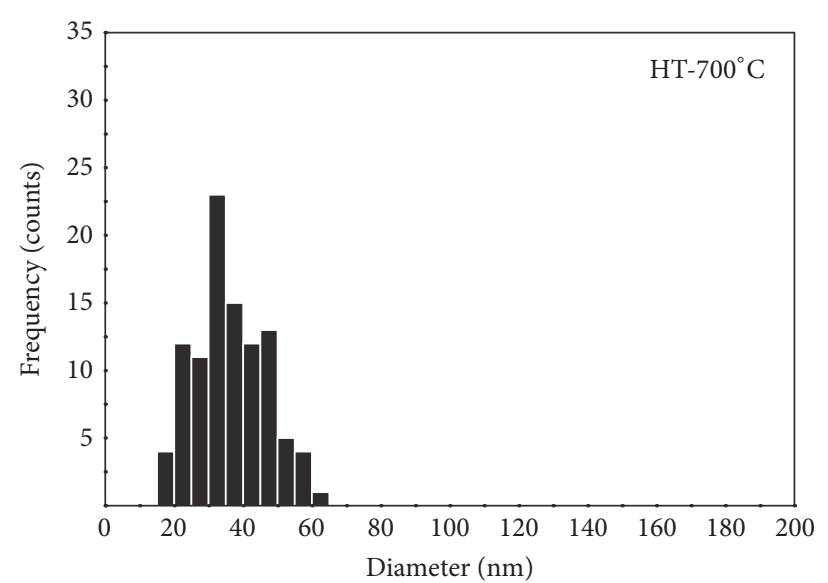

(b)

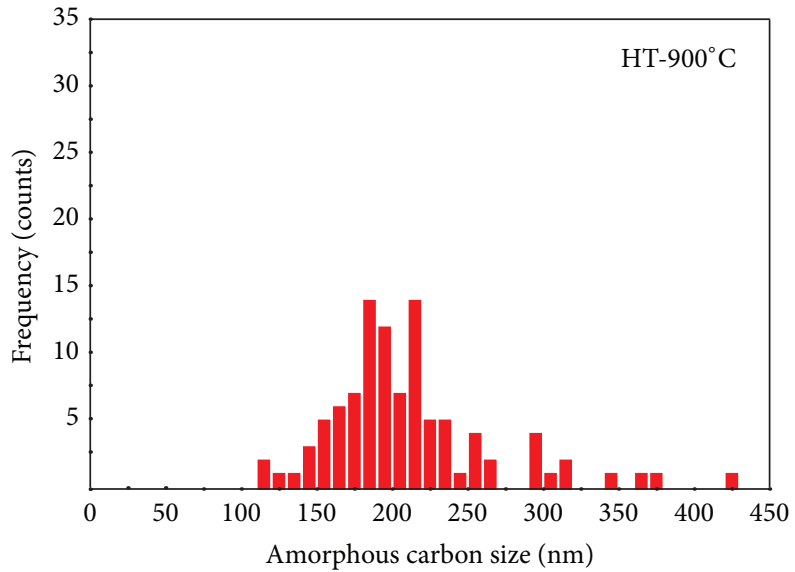

(d)

FIGURE 4: Size distribution of: MWCNTs (a)-(c) and amorphous carbon films (d). 


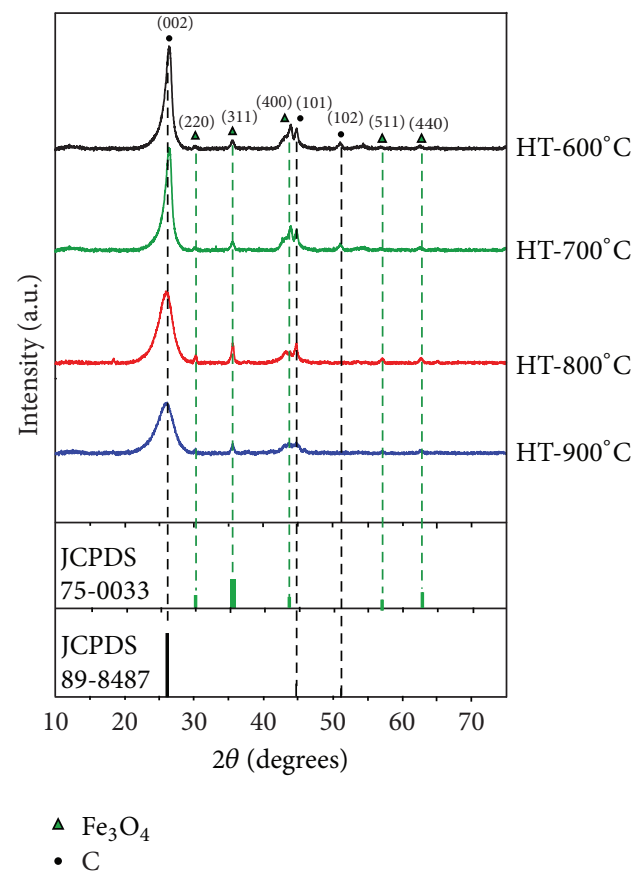

FIGURE 5: X-ray diffraction patterns of MWCNTs and amorphous carbon films (blue line) grown on heated substrate temperatures of 600, 700,800 , and $900^{\circ} \mathrm{C}$.

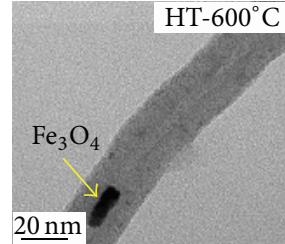

(a)

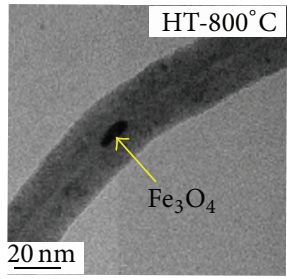

(c)

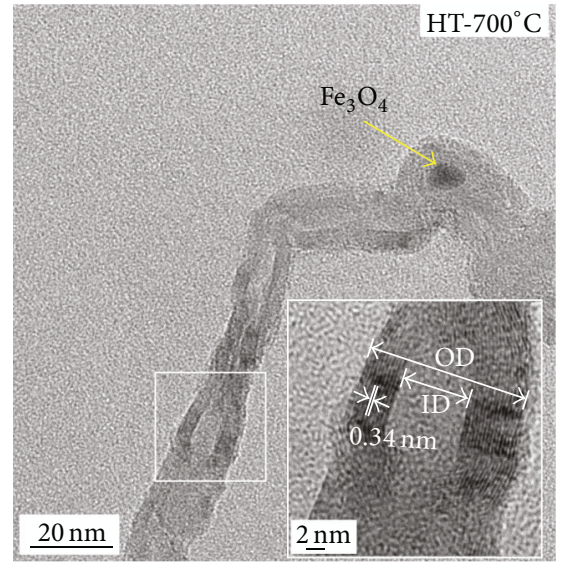

(b)

FIGURE 6: TEM images of synthesized MWCNTs and $\mathrm{Fe}_{3} \mathrm{O}_{4}$ catalytic particle grown on heated substrate temperatures of (a) $600^{\circ} \mathrm{C},(\mathrm{b}) 700^{\circ} \mathrm{C}$, and (c) $800^{\circ} \mathrm{C}$, respectively.

$\pm 17.0,43.0 \pm 8.5$, and $33.1 \pm 21.1 \mathrm{~nm}$, respectively. However, more MWCNTs were grown on substrate heated at $700^{\circ} \mathrm{C}$. At this temperature, the diameter of MWCNTs was found to be in the range of $10-60 \mathrm{~nm}$.

The crystallinity and purity of MWCNTs as investigated using a powder X-ray diffractometer (XRD) are shown in Figure 5. The dominant peak (002), according to JCPDS file number 89-8487, corresponding to carbon element was observed for all heated substrates. The lowest diffraction peak was observed for the substrate heated at $900^{\circ} \mathrm{C}$ because the amorphous carbon was grown at this temperature. This result is in good agreement with the result of SEM image. As can be seen from Figure 5, the diffraction peak decreased when the heated substrate temperatures were decreased from 600 to $800^{\circ} \mathrm{C}$. This is because the diameter of MWCNTs decreased with increasing of the heated substrate temperature. Again, the results are in good agreement with the results of SEM images. In Figure 5, the peaks (220), (311), (400), (511), and (440), according to JCPDS file number 75-0033, corresponding to $\mathrm{Fe}_{3} \mathrm{O}_{4}$ were observed.

Figure 6 shows the TEM images of MWCNTs for heated substrate temperatures of 600,700 , and $800^{\circ} \mathrm{C}$. As mentioned earlier from the SEM images nonuniform MWCNTs were observed for both heated substrate temperatures of 600 and 


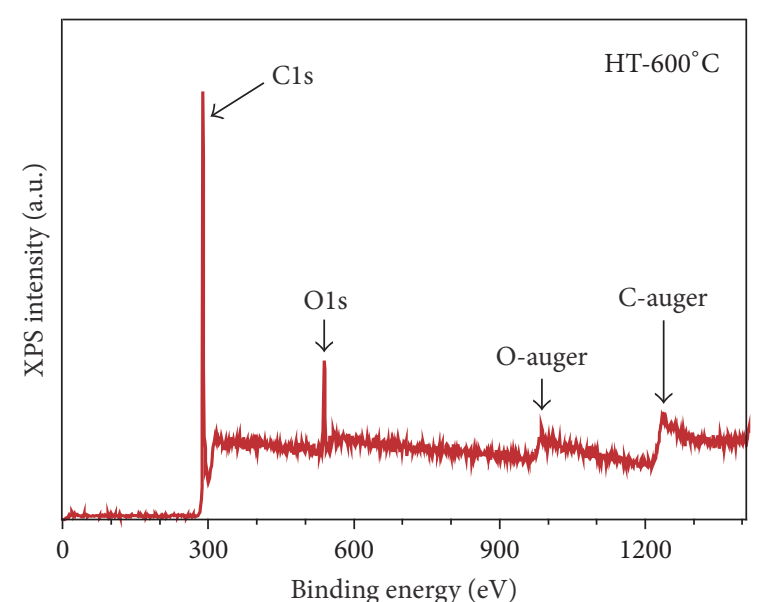

(a)

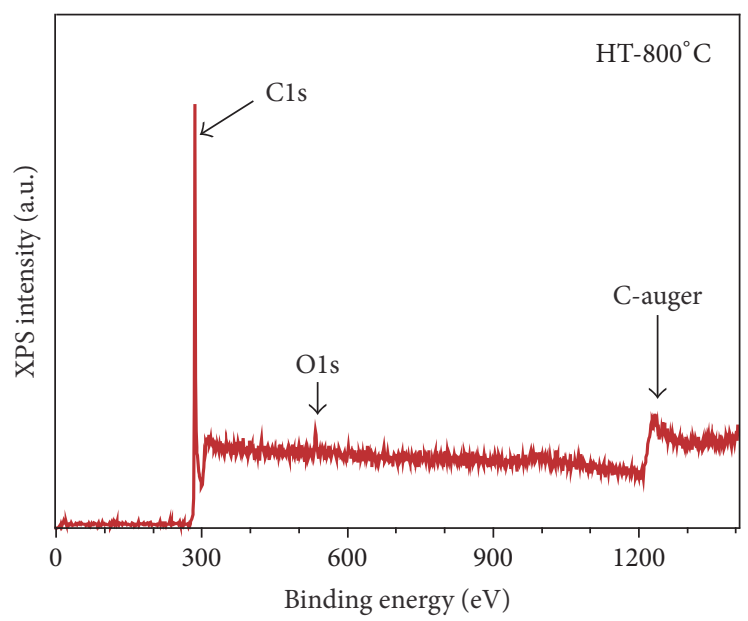

(c)

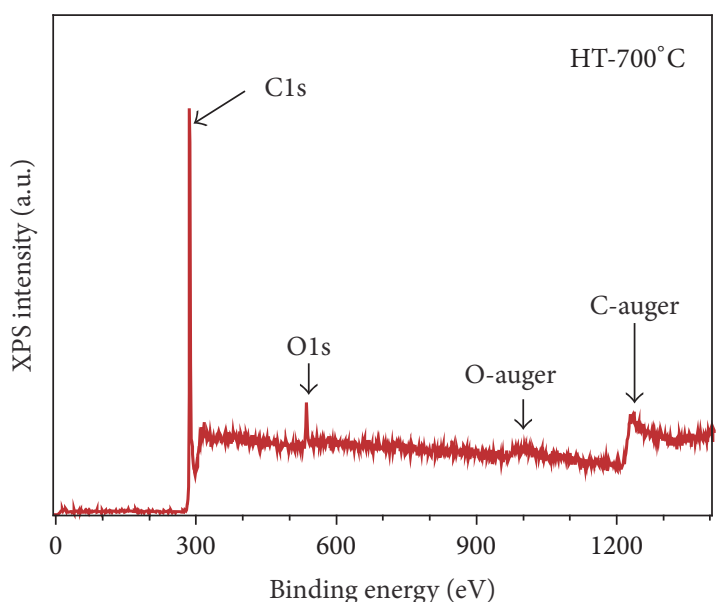

(b)

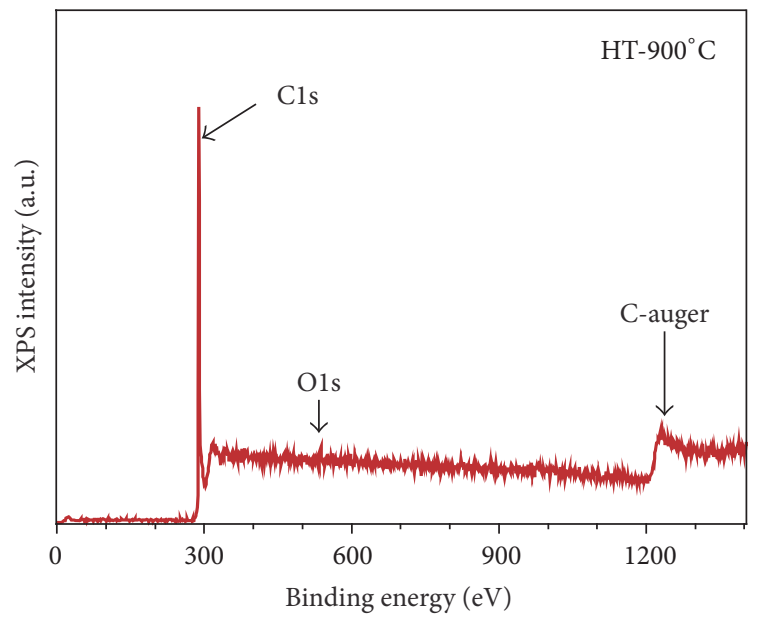

(d)

FIGURE 7: XPS survey scan of MWCNTs and amorphous carbon films.

$800^{\circ} \mathrm{C}$. Therefore, it should not be further discussed on the details of inner tube diameter of MWCNTs. Figure 6(b) shows the details of inner and outer tube diameters of MWCNTs for heated stainless steel substrate temperature of $700^{\circ} \mathrm{C}$. The inner and outer diameters of MWCNTs were found to be in the range of 8-10 and 15-18 nm, respectively. Furthermore, MWCNTs were clearly observed as shown in Figure 6(b) with 21 graphitic walls and the wall separation was approximately $0.34 \mathrm{~nm}$. In Figures 6(a)-6(c), the black small areas corresponding to $\mathrm{Fe}_{3} \mathrm{O}_{4}$ were also observed. It can be concluded that the TEM images agree well with the XRD results.

Figure 7 shows the survey scanned XPS spectra of MWCNTs (Figures 7(a)-7(c)) and amorphous carbon films (Figure $7(\mathrm{~d})$ ). All spectra present the chemical states of $\mathrm{Cls}$, $\mathrm{O} 1 \mathrm{~s}$, and $\mathrm{C}$-auger. The $\mathrm{C}$-auger peaks at the binding energy above $1200 \mathrm{eV}$ correspond to Auger electron emission as a result of passing between KLL levels of carbon. Furthermore, $\mathrm{O}$-auger peaks were only observed on the substrates heated at 600 and $700^{\circ} \mathrm{C}$.
TABLE 1: Binding energies and atomic concentrations of C1s and $\mathrm{O} 1 \mathrm{~s}$ for MWCNTs and amorphous carbon films.

\begin{tabular}{lcccc}
\hline \multirow{2}{*}{ Heated temperature $\left({ }^{\circ} \mathrm{C}\right)$} & \multicolumn{2}{c}{$\begin{array}{c}\text { Binding energy } \\
(\mathrm{eV})\end{array}$} & \multicolumn{2}{c}{$\begin{array}{c}\text { Atomic concentration } \\
(\text { at. \%) }\end{array}$} \\
& $\mathrm{C} 1 \mathrm{~s}$ & $\mathrm{O} 1 \mathrm{~s}$ & $\mathrm{C} 1 \mathrm{~s}$ & $\mathrm{O} 1 \mathrm{~s}$ \\
\hline 600 & 284 & 532 & 92.49 & 7.51 \\
700 & 284 & 533 & 96.33 & 3.67 \\
800 & 284 & 532 & 98.27 & 1.73 \\
900 & 284 & 533 & 98.37 & 1.63 \\
\hline
\end{tabular}

The binding energies and atomic concentrations of C1s and O1s for MWCNTs and amorphous carbon films are listed in Table 1. The atomic concentrations of $\mathrm{Cls}$ and $\mathrm{O} 1 \mathrm{~s}$ as a function of heated substrate temperature are shown in Figure 9.

It is seen from Table 1 and Figure 9 that the atomic concentration of C1s increased from $92.49 \%$ to $98.27 \%$ when 


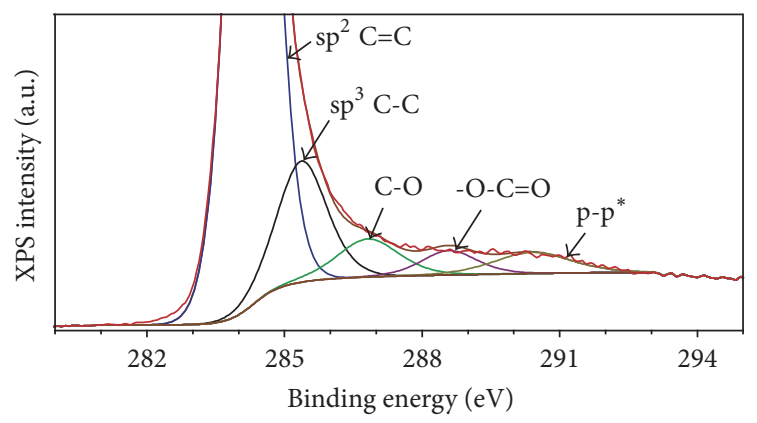

(a)

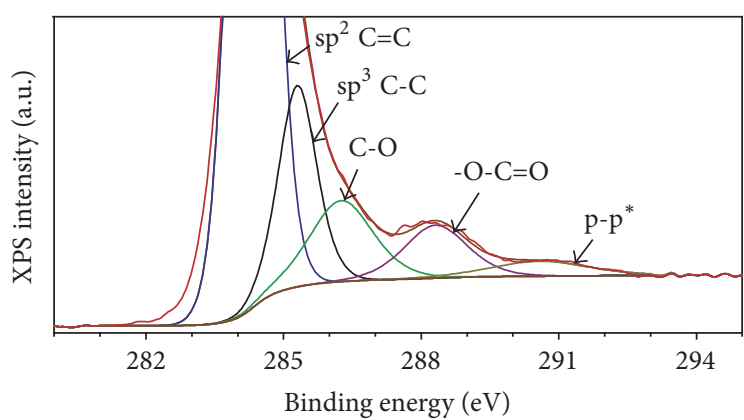

(c)

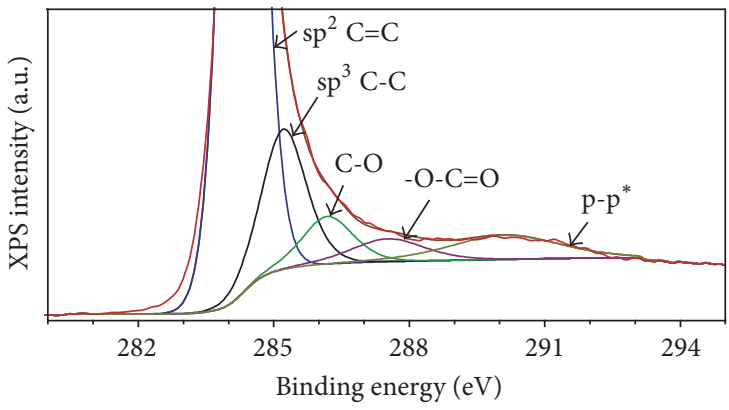

(b)

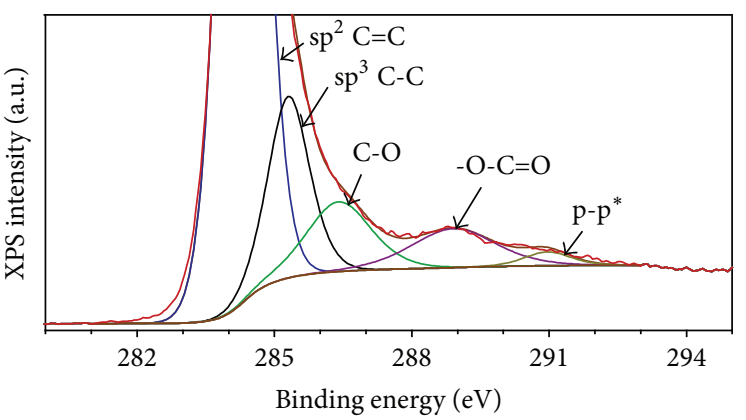

(d)

FIGURE 8: XPS deconvolution of MWCNTs and amorphous carbon films.

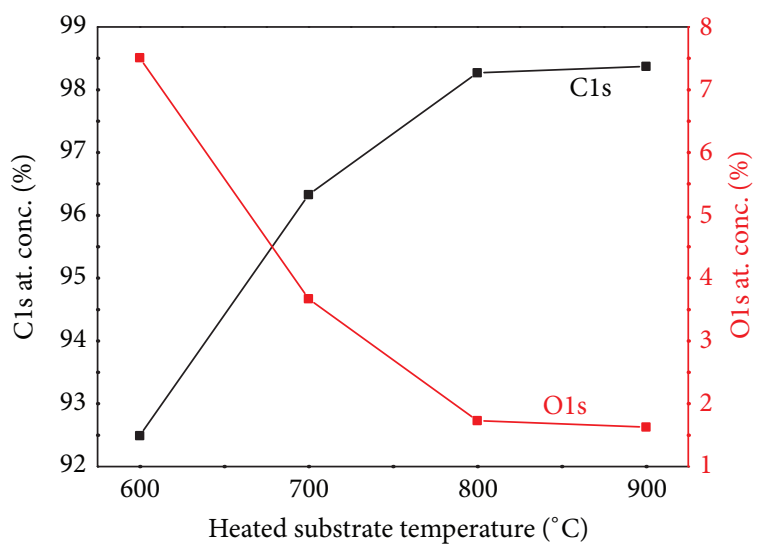

FIgURE 9: Atomic concentrations of Cls and O1s for MWCNTs and amorphous carbon films.

the substrate was heated from 600 to $900^{\circ} \mathrm{C}$, whereas the atomic concentration of O1s decreased from $7.51 \%$ to $1.73 \%$.

The Cls spectra in Figure 8 were deconvoluted using the Gaussian-Lorentzian curve fit to extract the chemical bond. The Cls spectra were fitted into five components as shown in Figure 8. The components correspond to the bonds of $\mathrm{sp}^{2} \mathrm{C}=\mathrm{C}, \mathrm{sp}^{3} \mathrm{C}-\mathrm{C}, \mathrm{C}-\mathrm{O}, \mathrm{O}-\mathrm{C}=\mathrm{O}$, and $\mathrm{p}-\mathrm{p}^{*}$ peak at binding energies of 284.3 [45], 285.3 [45], 286.2 [45, 46], 287.5 [45, 46], and $291.5 \mathrm{eV}$ [46], respectively.

The binding energies and atomic concentrations of chemical bonds are given in Table 2. The plots between $\mathrm{sp}^{3} / \mathrm{sp}^{2}$ bonding ratio and heated substrate temperature are shown in

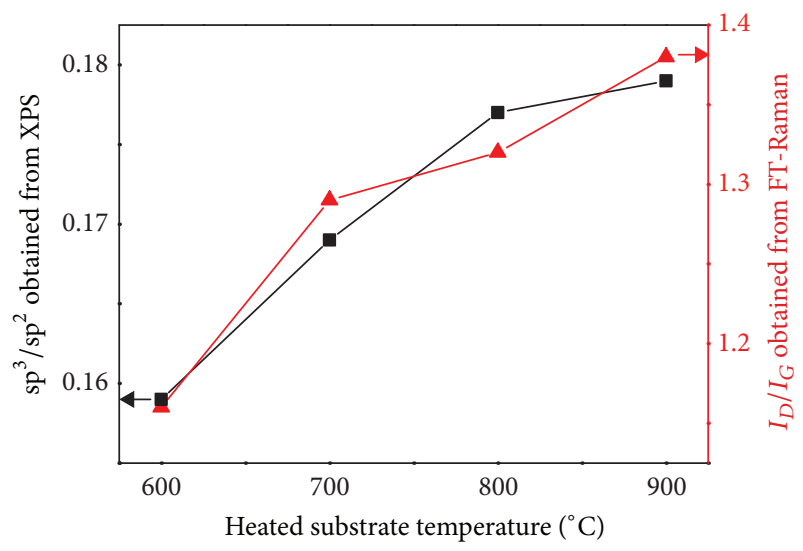

Figure 10: $\mathrm{sp}^{3} / \mathrm{sp}^{2}$ and $I_{D} / I_{G}$ values of MWCNTs and amorphous carbon films.

Figure 10. It is seen that the bond ratio of $\mathrm{sp}^{3} / \mathrm{sp}^{2}$ increased with increasing heated substrate temperature.

Figure 11 shows the visible Raman spectra from 900 to $2000 \mathrm{~cm}^{-1}$ of MWCNTs and amorphous carbon films. Table 3 shows the $D$-peak position, $G$-peak position, $D$-peak intensity, $G$-peak intensity, and the intensity ratio of $D$ band to $G$ band $\left(I_{D} / I_{G}\right)$. The $D$ and $G$ peaks were observed at about 1340 and $1582 \mathrm{~cm}^{-1}$, respectively. The plots of $I_{D} / I_{G}$ ratio as a function of heated substrate temperature are also shown in Figure 10. It is seen that $I_{D} / I_{G}$ ratio obtained from FT-Raman spectroscopy is correlated to $\mathrm{sp}^{3} / \mathrm{sp}^{2}$ bonding ratio obtained from XPS, representing the crystalline quality of MWCNTs. 
TABLE 2: Atomic concentrations of $\mathrm{sp}^{2} \mathrm{C}=\mathrm{C}$ and $\mathrm{sp}^{3} \mathrm{C}-\mathrm{C}$ for MWCNTs and amorphous carbon films.

\begin{tabular}{lccc}
\hline Heated temperature $\left({ }^{\circ} \mathrm{C}\right)$ & $\mathrm{sp}^{2} \mathrm{C}=\mathrm{C}$ & $\mathrm{sp}^{3} \mathrm{C}-\mathrm{C}$ & $\mathrm{sp}^{3} / \mathrm{sp}^{2}$ ratio \\
\hline 600 & Atomic concentration (at. \%) & Atomic concentration (at. \%) & 0.159 \\
700 & 77.09 & 12.23 & 0.169 \\
800 & 74.07 & 12.52 & 0.177 \\
900 & 71.24 & 12.58 & 0.179 \\
\hline
\end{tabular}

TABLE 3: Raman parameters of MWCNTs and amorphous carbon films grown on heated stainless steel substrate temperatures of $600-900^{\circ} \mathrm{C}$.

\begin{tabular}{lcccc}
\hline \multirow{2}{*}{ Heated temperature $\left({ }^{\circ} \mathrm{C}\right)$} & \multicolumn{2}{c}{ Raman shift $\left(\mathrm{cm}^{-1}\right)$} & \multicolumn{2}{c}{ Intensity (a.u.) } \\
& $D$-peak & $G$-peak & D-peak & $I_{D} / I_{G}$ \\
\hline 600 & 1340 & 1582 & 0.2659 & 0.2295 \\
700 & 1338 & 1582 & 0.1759 & 0.1364 \\
800 & 1335 & 1582 & 0.1230 & 0.0933 \\
900 & 1341 & 1578 & 0.1365 & 1.29 \\
\hline
\end{tabular}

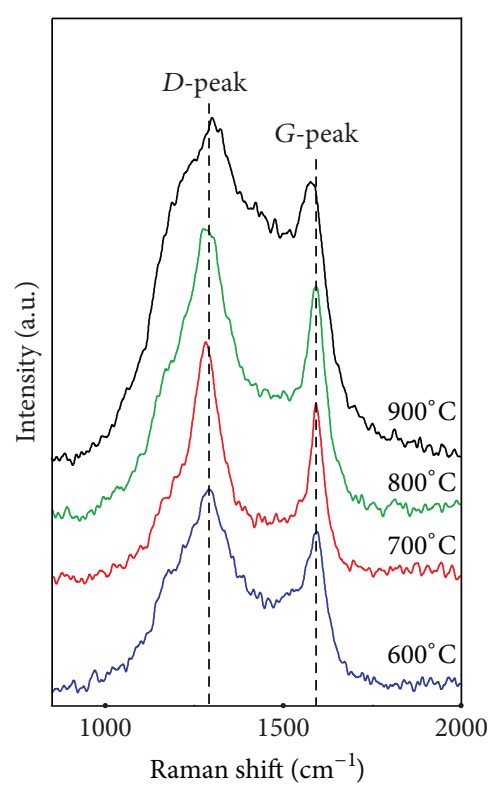

FIGURE 11: Raman spectra of MWCNTs and amorphous carbon films (blue line) grown on heated stainless steel substrate temperatures of $600,700,800$, and $900^{\circ} \mathrm{C}$.

The results shown in Figure 10 illustrate that the defect of MWCNTs and amorphous carbon increased with increasing heated substrate temperatures.

Therefore, the degree of crystallinity of MWCNTs grown at higher heated substrate temperature is very low because of the occurrence of amorphous carbons. Interestingly, these results are strongly consistent with the results obtained from XRD and XPS.

To understand the effects of heated substrate on the formation of amorphous carbon films, the pure substrates heated at $900^{\circ} \mathrm{C}$ were further investigated. For comparison, the substrate heated at $700^{\circ} \mathrm{C}$ was also carried out. Both samples were mounted with epoxy resin followed by the polishing procedure of SiC grinding papers. The cross-sectional SEM images and energy dispersive spectroscopy (EDS) line scan profiles in the range of $3.75 \mu \mathrm{m}$ (as shown by red arrows in Figure 12) were then taken. Figure 13 shows the line scan profiles of $\mathrm{Fe}, \mathrm{Cr}, \mathrm{Ni}$, and oxygen as a function of the distance in the range of $3.75 \mu \mathrm{m}$ from the surface. It is seen that the concentrations of $\mathrm{Ni}$ and oxygen did not differ for both heated temperatures while the concentrations of $\mathrm{Fe}$ and $\mathrm{Cr}$ showed a remarkable increase at high heated temperature, that is, $900^{\circ} \mathrm{C}$. It indicated that the Fe-rich clusters could diffuse to the surface and formed $\mathrm{Fe}_{3} \mathrm{O}_{4}$. This can be explained by schematic as shown in Figure 14. Therefore, the Fe-rich clusters were created as $\mathrm{Fe}_{3} \mathrm{O}_{4}$ on the substrate heated at $900^{\circ} \mathrm{C}$. Hence, the $\mathrm{Fe}_{3} \mathrm{O}_{4}$ lead to the formation of amorphous carbon films. In contrast, the lower concentration of Fe element acts as catalysts and enhanced the MWCNT formation at lower heated substrate temperatures of $600-800^{\circ} \mathrm{C}$ without using an additional catalyst.

\section{Conclusions}

In summary, the MWCNTs and amorphous carbon films were synthesized on austenitic stainless steel substrates using a home-built thermal CVD system. The surface of the flexible stainless steel was activated by hydrogen at different temperatures of 600,700800 , and $900^{\circ} \mathrm{C}$. The effects of the heated substrate temperatures on the crystalline structure and the size of MWCNTs were investigated. The results show that the diameter of MWCNTs decreased with increasing the temperature of heated substrate. The better uniformity of MWCNTs was observed on the substrate heated at $700^{\circ} \mathrm{C}$. Furthermore, the amorphous carbon instead of MWCNT was observed on the substrate heated at $900^{\circ} \mathrm{C}$. The degree of crystallinity of MWCNTs grown at higher heated substrate temperature is very low because of the occurrence of amorphous carbons. The observation of $\mathrm{Fe}_{3} \mathrm{O}_{4}$ nanoparticles in XRD patterns and TEM images strongly confirms that among $\mathrm{Fe}, \mathrm{Ni}, \mathrm{Mn}$, and $\mathrm{Cr}$ elements contained in stainless steel, only 


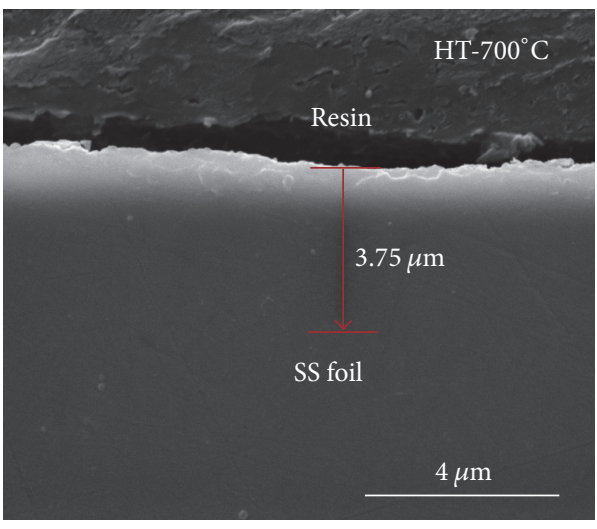

(a)

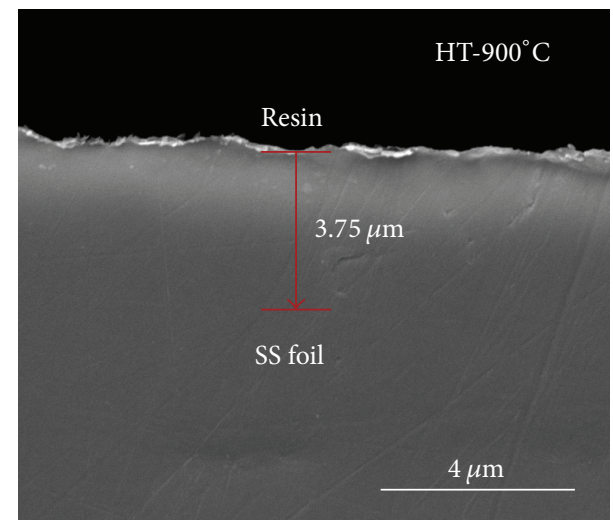

(b)

FIGURE 12: Cross-sectional SEM images of the substrates heated at (a) $700^{\circ} \mathrm{C}$ and (b) $900^{\circ} \mathrm{C}$.

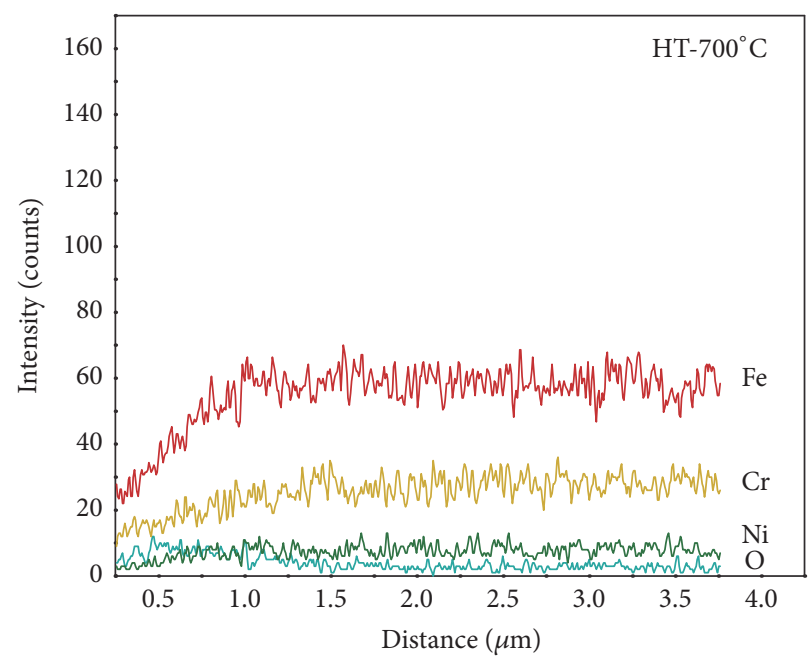

(a)

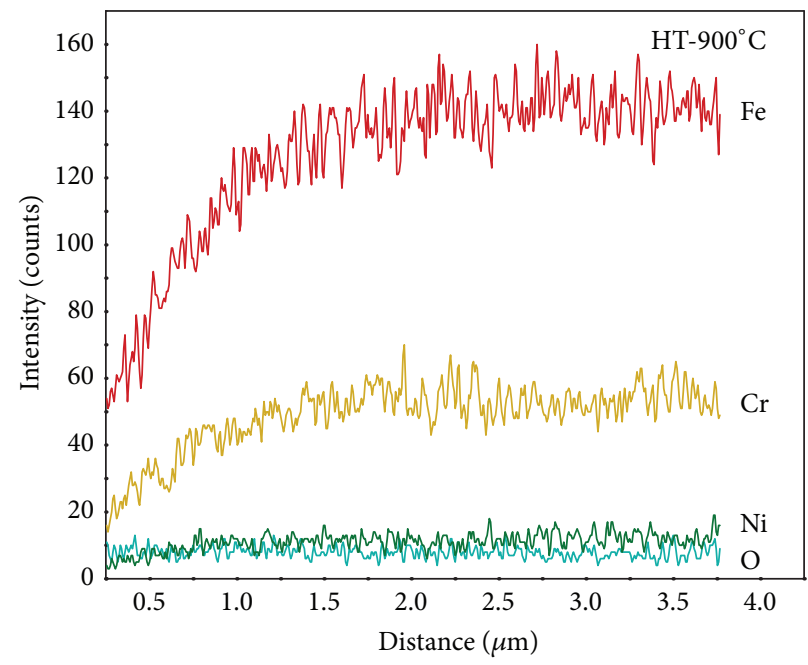

(b)

Figure 13: EDS line scan profiles of the substrates heated at (a) $700^{\circ} \mathrm{C}$ and (b) $900^{\circ} \mathrm{C}$.

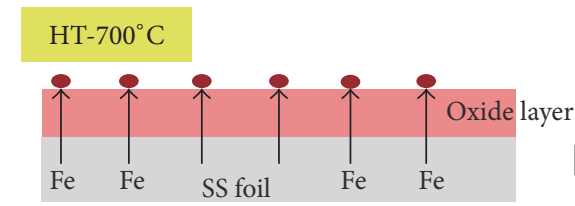

CVD process

(a)
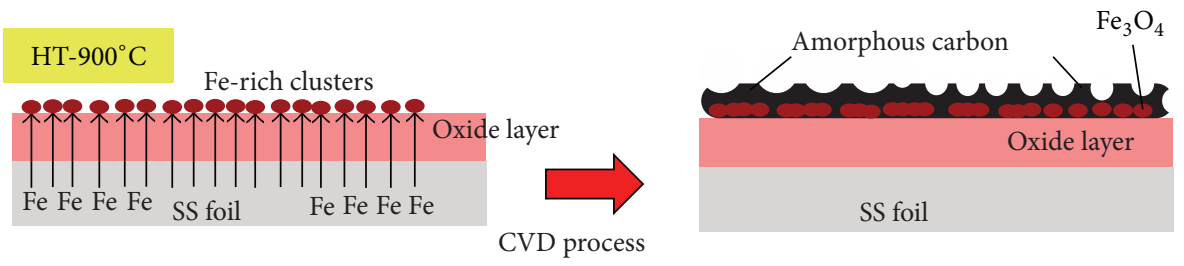

(b)

FIGURE 14: Growth mechanism of MWCNTs and amorphous carbon films grown on the substrates heated at (a) $700^{\circ} \mathrm{C}$ and (b) $900^{\circ} \mathrm{C}$. 
Fe element acted as catalysts. The XPS results showed the chemical states of the purely carbon films as C1s and O1s. The deconvoluted XPS spectra of C1s revealed the covalent bonds of carbon-carbon bonds $\left(\mathrm{sp}^{2}\right.$ and $\left.\mathrm{sp}^{3}\right)$ and carbonoxygen bonds $(\mathrm{C}=\mathrm{O}$ and $\mathrm{O}-\mathrm{C}=\mathrm{O})$. As a result, the $\mathrm{Cl}$ s core level spectra of the carbon films were a function of heated substrate temperatures. The results obtained from this work showed that the simple method can be used effectively for the growth of MWCNT on flexible stainless steel at a suitable temperature. The obtained results are possible for widely used in some applications such as flexible electrodes and flexible batteries due to their flexible characters.

\section{Conflicts of Interest}

The authors declare that they have no conflicts of interests regarding the publication of this paper.

\section{Acknowledgments}

This work was supported by Department of Physics, Faculty of Science, Kasetsart University, Thailand. The authors are grateful for the grant supported by the SUT-NANOTEC-SLRI Joint Research Facility, Synchrotron Light Research Institute, Thailand, for the XPS analysis.

\section{References}

[1] S. Iijima, "Helical microtubules of graphitic carbon," Nature, vol. 354, no. 6348, pp. 56-58, 1991.

[2] Y. S. Park, K. S. Kim, H. J. Jeong et al., "Low pressure synthesis of single-walled carbon nanotubes by arc discharge," Synthetic Metals, vol. 126, no. 2-3, pp. 245-251, 2002.

[3] M. Jinno, S. Bandow, and Y. Ando, "Multiwalled carbon nanotubes produced by direct current arc discharge in hydrogen gas," Chemical Physics Letters, vol. 398, no. 1-3, pp. 256-259, 2004.

[4] Y. Su, Z. Yang, H. Wei, E. S.-W. Kong, and Y. Zhang, "Synthesis of single-walled carbon nanotubes with selective diameter distributions using DC arc discharge under CO mixed atmosphere," Applied Surface Science, vol. 257, no. 7, pp. 3123-3127, 2011.

[5] K. H. Maria and T. Mieno, "Synthesis of single-walled carbon nanotubes by low-frequency bipolar pulsed arc discharge method," Vacuum, vol. 113, pp. 11-18, 2015.

[6] C. D. Scott, S. Arepalli, P. Nikolaev, and R. E. Smalley, "Growth mechanisms for single-wall carbon nanotubes in a laserablation process," Applied Physics A, vol. 72, no. 5, pp. 573-580, 2001.

[7] L. Lascialfari, P. Marsili, S. Caporali et al., "Carbon nanotubes/ laser ablation gold nanoparticles composites," Thin Solid Films, vol. 569, pp. 93-99, 2014.

[8] S. Xie, W. Li, Z. Pan, B. Chang, and L. Sun, "Carbon nanotube arrays," Materials Science and Engineering A, vol. 286, no. 1, pp. $11-15,2000$.

[9] O. Noury, T. Stöckli, M. Croci, and A. Châtelain Jean-Marc Bonard, "Growth of carbon nanotubes on cylindrical wires by thermal chemical vapor deposition," Chemical Physics Letters, vol. 346, no. 5-6, pp. 349-355, 2001.

[10] M. Jung, K. Y. Eun, J.-K. Lee, Y.-J. Baik, K.-R. Lee, and J. Wan Park, "Growth of carbon nanotubes by chemical vapor deposition," Diamond and Related Materials, vol. 10, no. 3, pp. 1235-1240, 2001.

[11] C. J. Lee, J. Park, and J. A. Yu, "Catalyst effect on carbon nanotubes synthesized by thermal chemical vapor deposition," Chemical Physics Letters, vol. 360, no. 3-4, pp. 250-255, 2002.

[12] C. E. Baddour, F. Fadlallah, D. Nasuhoglu, R. Mitra, L. Vandsburger, and J.-L. Meunier, "A simple thermal CVD method for carbon nanotube synthesis on stainless steel 304 without the addition of an external catalyst," Carbon, vol. 47, no. 1, pp. 313318, 2009.

[13] F. Cervantes-Sodi, J. J. Vilatela, J. A. Jiménez-Rodríguez et al., "Carbon nanotube bundles self-assembled in double helix microstructures," Carbon, vol. 50, no. 10, pp. 3688-3693, 2012.

[14] A. V. Gaikwad, T. K. Rout, D. Van Der Plas et al., "Carbon nanotube/carbon nanofiber growth from industrial by-product gases on low- and high-alloy steels," Carbon, vol. 50, no. 12, pp. 47224731, 2012.

[15] P. Romero, R. Oro, M. Campos, J. M. Torralba, and R. G. De Villoria, "Simultaneous synthesis of vertically aligned carbon nanotubes and amorphous carbon thin films on stainless steel," Carbon, vol. 82, pp. 31-38, 2015.

[16] L. Yuan, K. Saito, W. Hu, and Z. Chen, "Ethylene flame synthesis of well-aligned multi-walled carbon nanotubes," Chemical Physics Letters, vol. 346, no. 1-2, pp. 23-28, 2001.

[17] L. Yuan, K. Saito, C. Pan, F. A. Williams, and A. S. Gordon, "Nanotubes from methane flames," Chemical Physics Letters, vol. 340, no. 3-4, pp. 237-241, 2001.

[18] M. J. Height, J. B. Howard, J. W. Tester, and J. B. V. Sande, "Flame synthesis of single-walled carbon nanotubes," Carbon, vol. 42, no. 11, pp. 2295-2307, 2004.

[19] H. Oulanti, F. Laurent, T. Le-Huu, B. Durand, and J. B. Donnet, "Growth of carbon nanotubes on carbon fibers using the combustion flame oxy-acetylene method," Carbon, vol. 95, pp. 261-267, 2015.

[20] G.-B. Zheng, K. Kouda, H. Sano, Y. Uchiyama, Y.-F. Shi, and H.-J. Quan, "A model for the structure and growth of carbon nanofibers synthesized by the CVD method using nickel as a catalyst," Carbon, vol. 42, no. 3, pp. 635-640, 2004.

[21] I. Martin-Gullon, J. Vera, J. A. Conesa, J. L. González, and C. Merino, "Differences between carbon nanofibers produced using $\mathrm{Fe}$ and Ni catalysts in a floating catalyst reactor," Carbon, vol. 44, no. 8, pp. 1572-1580, 2006.

[22] K. Voelskow, M. J. Becker, W. Xia, M. Muhler, and T. Turek, “The influence of kinetics, mass transfer and catalyst deactivation on the growth rate of multiwalled carbon nanotubes from ethene on a cobalt-based catalyst," Chemical Engineering Journal, vol. 244, pp. 68-74, 2014.

[23] S. S. Madani, K. Zare, M. Ghoranneviss, and A. S. Elahi, "Synthesis of carbon nanotubes using the cobalt nanocatalyst by thermal chemical vapor deposition technique," Journal of Alloys and Compounds, vol. 648, pp. 1104-1108, 2015.

[24] M. Pérez-Cabero, A. Monzón, I. Rodríguez-Ramos, and A. Guerrero-Ruíz, "Syntheses of CNTs over several iron-supported catalysts: influence of the metallic precursors," Catalysis Today, vol. 93-95, pp. 681-687, 2004.

[25] J. Jiang, T. Feng, X. Cheng et al., "Synthesis and growth mechanism of Fe-catalyzed carbon nanotubes by plasma-enhanced chemical vapor deposition," Nuclear Instruments and Methods in Physics Research, Section B: Beam Interactions with Materials and Atoms, vol. 244, no. 2, pp. 327-332, 2006. 
[26] L. Camilli, M. Scarselli, S. Del Gobbo et al., "The synthesis and characterization of carbon nanotubes grown by chemical vapor deposition using a stainless steel catalyst," Carbon, vol. 49, no. 10, pp. 3307-3315, 2011.

[27] M. Hashempour, A. Vicenzo, F. Zhao, and M. Bestetti, "Direct growth of MWCNTs on 316 stainless steel by chemical vapor deposition: effect of surface nano-features on CNT growth and structure," Carbon, vol. 63, pp. 330-347, 2013.

[28] V. Martínez-Hansen, N. Latorre, C. Royo, E. Romeo, E. GarcíaBordejé, and A. Monzón, "Development of aligned carbon nanotubes layers over stainless steel mesh monoliths," Catalysis Today, vol. 147, pp. S71-S75, 2009.

[29] C.-L. Lin, C.-F. Chen, and S.-C. Shi, "Field emission properties of aligned carbon nanotubes grown on stainless steel using $\mathrm{CH} 4 / \mathrm{CO}_{2}$ reactant gas," Diamond and Related Materials, vol. 13, no. 4-8, pp. 1026-1031, 2004.

[30] R. L. Vander Wal and L. J. Hall, "Carbon nanotube synthesis upon stainless steel meshes," Carbon, vol. 41, no. 4, pp. 659-672, 2003.

[31] L. Z. Gao, L. Kiwi-Minsker, and A. Renken, "Growth of carbon nanotubes and microfibers over stainless steel mesh by cracking of methane," Surface and Coatings Technology, vol. 202, no. 13, pp. 3029-3042, 2008.

[32] C. Zhuo, B. Hall, H. Richter, and Y. Levendis, "Synthesis of carbon nanotubes by sequential pyrolysis and combustion of polyethylene," Carbon, vol. 48, no. 14, pp. 4024-4034, 2010.

[33] C. Zhuo, X. Wang, W. Nowak, and Y. A. Levendis, "Oxidative heat treatment of 316L stainless steel for effective catalytic growth of carbon nanotubes," Applied Surface Science, vol. 313, pp. 227-236, 2014.

[34] S. Chandrakishore and A. Pandurangan, "Electrophoretic deposition of cobalt catalyst layer over stainless steel for the high yield synthesis of carbon nanotubes," Applied Surface Science, vol. 258, no. 20, pp. 7936-7942, 2012.

[35] S.-Y. Lee, M. Yamada, and M. Miyake, "Synthesis of carbon nanotubes over gold nanoparticle supported catalysts," Carbon, vol. 43, no. 13, pp. 2654-2663, 2005.

[36] C.-H. Wang, H.-Y. Du, H.-C. Hsu et al., "High stability of oxidation of methanol catalyzed by Pt supported by oxygenincorporated bamboo-shaped CNTs grown directly on carbon cloth," International Journal of Hydrogen Energy, vol. 37, no. 14, pp. 10663-10670, 2012.

[37] W. Z. Li, D. Z. Wang, S. X. Yang, J. G. Wen, and Z. F. Ren, "Controlled growth of carbon nanotubes on graphite foil by chemical vapor deposition," Chemical Physics Letters, vol. 335, no. 3-4, pp. 141-149, 2001.

[38] C.-C. Su and S.-H. Chang, "Effective growth of vertically aligned carbon nanotube turfs on flexible Al foil," Materials Letters, vol. 65, no. 17-18, pp. 2700-2702, 2011.

[39] G. Atthipalli, R. Epur, P. N. Kumta et al., "The effect of temperature on the growth of carbon nanotubes on copper foil using a nickel thin film as catalyst," Thin Solid Films, vol. 519, no. 16, pp. 5371-5375, 2011.

[40] G. Atthipalli, H. Wang, and J. L. Gray, "Catalyst-assisted vertical growth of carbon nanotubes on Inconel coated commercial copper foil substrates versus sputtered copper films," Applied Surface Science, vol. 273, pp. 515-519, 2013.

[41] J. Zhu, J. Jia, F.-L. Kwong, and D. H. L. Ng, "Synthesis of bamboo-like carbon nanotubes on a copper foil by catalytic chemical vapor deposition from ethanol," Carbon, vol. 50, no. 7, pp. 2504-2512, 2012.
[42] G. Zhong, J. Yang, H. Sugime et al., "Growth of high quality, high density single-walled carbon nanotube forests on copper foils," Carbon, vol. 98, pp. 624-632, 2016.

[43] S. Yoon, S. Lee, S. Kim, K.-W. Park, D. Cho, and Y. Jeong, "Carbon nanotube film anodes for flexible lithium ion batteries," Journal of Power Sources, vol. 279, pp. 495-501, 2015.

[44] Y. Huang, H. Zhang, G. Zeng et al., “The microwave absorption properties of carbon-encapsulated nickel nanoparticles/silicone resin flexible absorbing material," Journal of Alloys and Compounds, vol. 682, pp. 138-143, 2016.

[45] T. I. T. Okpalugo, P. Papakonstantinou, H. Murphy, J. McLaughlin, and N. M. D. Brown, "High resolution XPS characterization of chemical functionalised MWCNTs and SWCNTs," Carbon, vol. 43, no. 1, pp. 153-161, 2005.

[46] V. Datsyuk, M. Kalyva, K. Papagelis et al., "Chemical oxidation of multiwalled carbon nanotubes," Carbon, vol. 46, no. 6, pp. 833-840, 2008. 

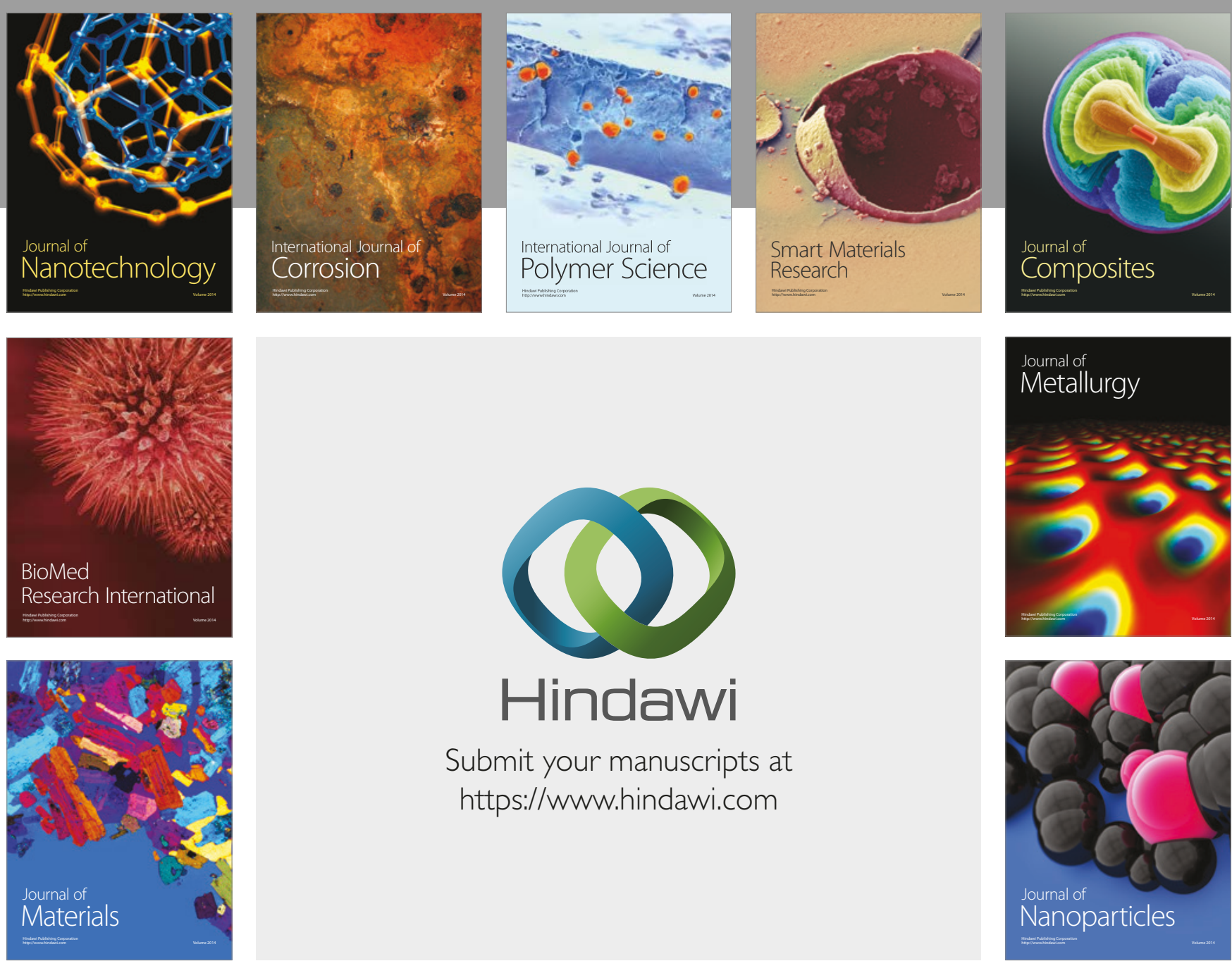

\section{Hindawi}

Submit your manuscripts at

https://www.hindawi.com
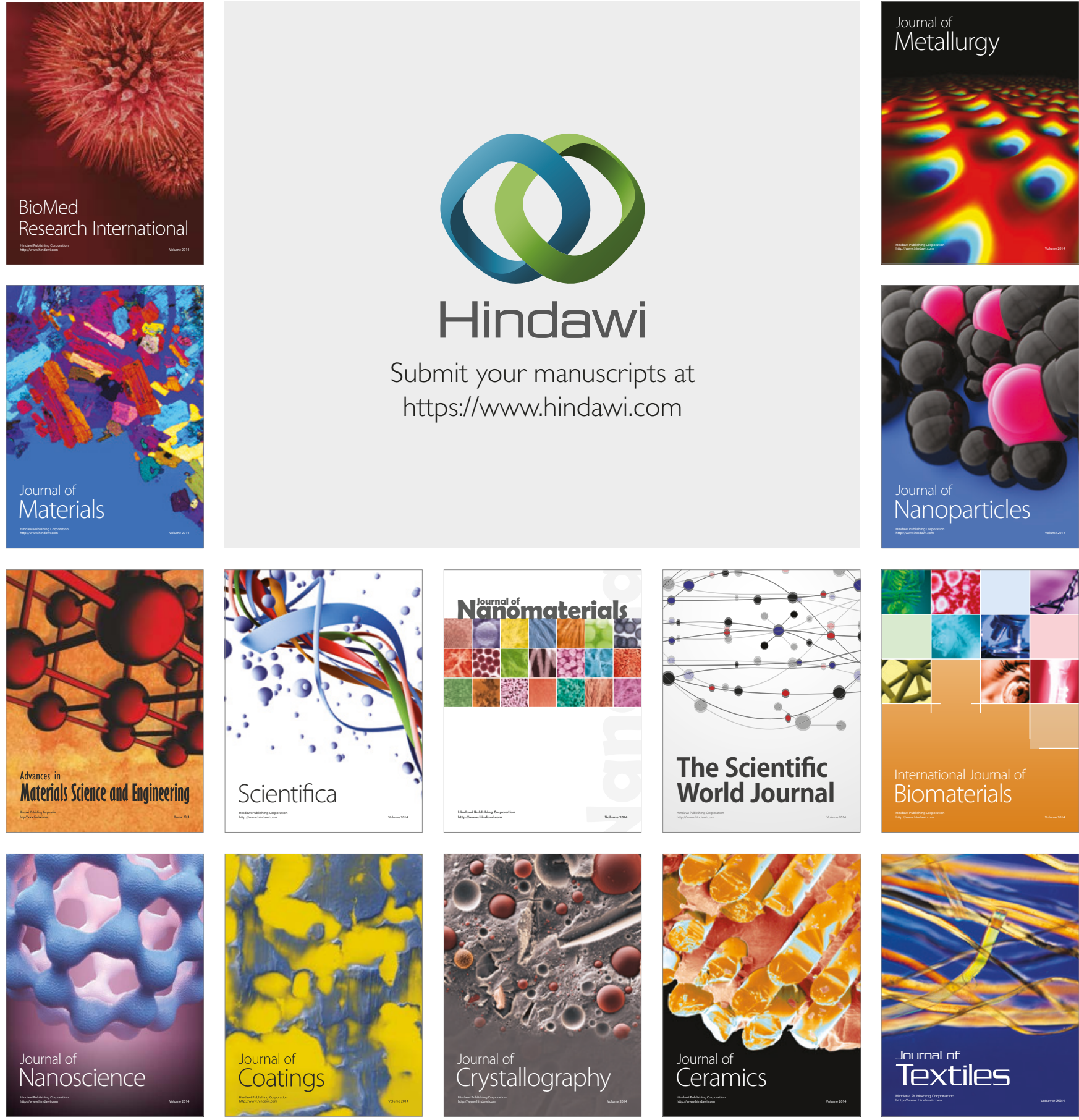

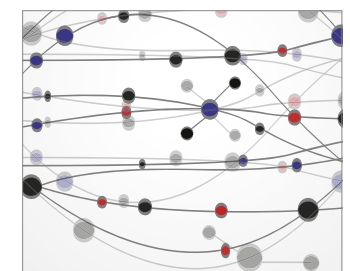

The Scientific World Journal
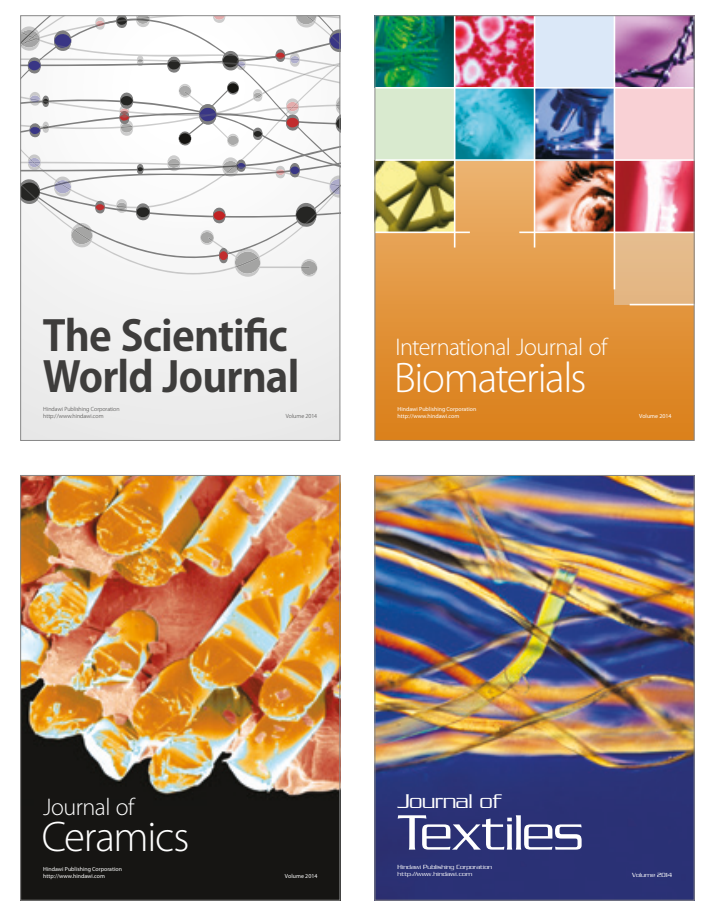